\title{
Axial Capacity Enhancement of CFRP Confined Columns Made of Steel Fiber Reinforced Concrete
}

\author{
Munshi Galib Muktadir ${ }^{1}$, Md. Mashfiqul Islam ${ }^{2}$ and Rasel Reza ${ }^{3}$ \\ ${ }^{1}$ Lecturer, Department of Civil Engineering, Ahsanullah University of Science and Technology, Dhaka, \\ Bangladesh, \\ ${ }^{2}$ Assistant Professor, Department of Civil Engineering, Ahsanullah University of Science and Technology, \\ Dhaka, Bangladesh, \\ ${ }^{3}$ Graduate, Department of Civil Engineering, Stamford University, Dhaka, Bangladesh,
}

\begin{abstract}
Results of the experimental study on the axial compressive behavior of steel fiber reinforced concrete (SFRC) wrapped with fiber reinforced polymer (FRP) have been presented in this paper. A total of 18 concrete cylinders were tested under axial compression. The effects of steel fiber parameters were investigated which includes fiber aspect ratio $(A R)$ and fiber volume fraction $(V F)$. The concrete cylinders were divided into groups of confined and unconfined ones. In accordance with previous study, it was found that, FRP confined cylinders showed greater axial stress than that of unconfined specimens. Although the presence of steel fiber increases the peak axial stresses for both confined and unconfined group of specimens, but no significant change of peak axial stress (and peak strain) has been observed in both confined and unconfined group due to increase of fiber volume ratio. But with the increase of fiber aspect ratio, the peak axial stresses of both unconfined and FRPconfined cylinders were found to slightly decrease. It was also observed that, concrete specimens reinforced with internal steel fiber absorbed much higher energy than that of unreinforced ones.
\end{abstract}

\section{Introduction}

Axially loaded concrete columns demonstrate enhanced strength and ductility when confined with fiber reinforced polymer (FRP) wrap at hoop direction (FRP wrap restrains lateral dilation) [1]. Due to dilation of concrete, confinement mechanism is mobilized and the lateral confining pressure develops in FRP wraps. This confining pressure on FRP arrests further dilation of concrete up to its own tensile strength and enhances the axial load carrying capacity of concrete columns [2]. The transverse FRP is loaded in tension due to concrete dilation, thus containing concrete after its internal cracking provides lateral confining pressure. Advanced composite materials-based systems currently show the greatest potential for cost-effective application in the area of retrofit and rehabilitation of reinforced concrete structures, especially as related to columnar elements repaired for either enhanced axial load-carrying capacity or enhanced seismic resistance through the use of FRP wraps. This follows from the previously known effect of column strengthening through lateral confinement, which stems from the development of a tri-axial stress state within the concrete, and its ultimate containment after dilation under load.

A comprehensive review of the literature reported in Refs. [3,4] shows the great number of studies on FRP-wrapped concrete columns and concrete-filled FRP tubes to investigate the axial compressive behavior of the members/ specimens. It is now well-understood that the confinement of concrete with fiber-reinforced polymer (FRP) composites significantly improves both compressive strength and ductility of concrete. However, due to inherently brittle nature of concrete, even well-confined concrete members exhibit drastic failure after the peak ultimate stress. This behavior negatively affects the overall performance of FRP confined concrete members, especially when subjected to dynamic load like earthquake. This fact entices encouragement to search for new composite structural systems that are able to maintain desirable properties of FRP-confined concrete, while overcoming its identified shortcomings.

For the past three decades, the behavior of steel fiber reinforced concrete (SFRC) has been widely studied [5-26]. From these studies it is found that the presence of internal steel fibers in concrete results in improvement of its strength and ductility. Studies show that, internal steel fibers form bridges across the crack of concrete and thus become effective in delaying and arresting crack propagation. [7,9,13-19,21-23,25]. Benefitting from this improved properties of concrete, FRP-confined steel fiber reinforced concrete (FRPconfined SFRC) may form an attractive composite system that is capable of overcoming the aforementioned shortcoming seen in FRP-confined concrete. However, review of existing literature reveals the fact that not enough study has been conducted to date on the behavior of FRP-confined SFRC specimens.

The study presented in this paper was aimed at examining the influence of key parameters for FRPconfined steel fiber reinforced concretes under axial load. The paper initially provides a description of the 
Experimental Investigation of Axial Capacity and Energy Absorption of SFRC Columns Confined ..

experimental program, including specimen properties and the testing procedure. After that, the results of the experiments are presented. Finally, an in-depth discussion on the results of the experiments is provided.

\section{Test program}

\subsection{Test specimens}

A total of 18 circular concrete specimens were manufactured with different volume fraction (VF) of steel fibers (i.e. $\mathrm{VF}=1.5 \%$ and $2.0 \%$ ) and aspect ratio (AR) of steel fibers (i.e. $\mathrm{AR}=20,40,60$ and 80 ). The specimens were $101.6 \mathrm{~mm}$ in diameter, measured at the concrete core, and $203.2 \mathrm{~mm}$ in height. All confined specimens were wrapped with FRP using a manual wet lay-up procedure.

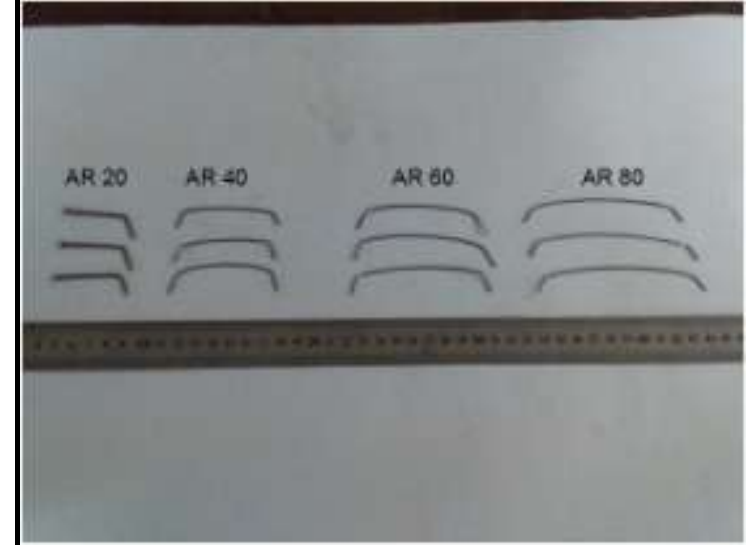

Fig. 1. Illustration of steel fibers

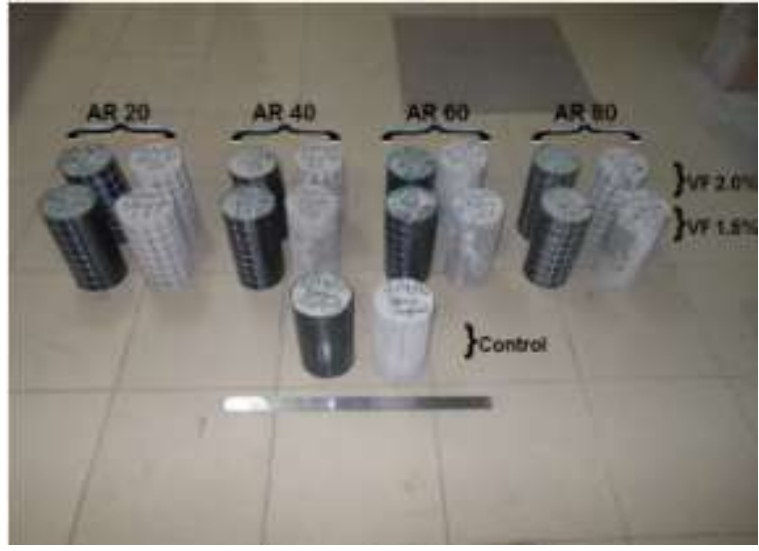

Fig. 2. Confined and Unconfined Concrete Cylinders

\subsection{Materials}

A mix ratio of 1:2:4 and a w/c ratio of 0.55 were used in manufacturing the concrete specimens. All the fibers used in this study were hooked end. In this experiment, stone aggregate were used as coarse aggregate. The FRP wrap used in this study was Nitowrap EP (CF200). The fibers were of unidirectional, weight of the wrap was $200 \mathrm{gsm}$, thickness was $0.11 \mathrm{~mm}$ and width of the fiber sheet was $508 \mathrm{~mm}$. Specimens were tested until failure occurred and the ultimate strength was recorded. The mixed material of Nitowrap 30 epoxy primer was used in this experiment. There were two agents, i.e. base and hardener. The mix ratio was 2:1. The epoxy adhesive was prepared by mixing epoxy resin and hardener in 2:1 ratio in accordance with the manufacturer's recommendation.

\subsection{Specimen designation}

The 18 specimens were labeled as follows:

Each label started with the letter $\mathrm{S}$ which stands for stone aggregate. For specimens (a total of 16) which were manufactured with internal steel fibers, S was followed by the term SF which stands for "Steel Fiber". Two specimens were manufactured without any internal steel fiber and for those specimens, $\mathrm{S}$ was followed by the term CON which stands for "Control". In specimens that contained steel fibers, the first part of the designation SSF was followed by the volume fraction of steel fibers (either 1.5 or 2.0), then a dash was used, and the dash was followed by aspect ratio of steel fiber (20, 40, 60 or 80). Finally, for FRP-confined specimens, the letter $\mathrm{C}$ was used to indicate confinement of concrete. For example, the term SSF1.5-60C indicates one of the specimens which contained steel fibers $(\mathrm{SF})$ in it with $1.5 \%$ volume fraction of steel fibers and with steel fibers aspect ratio of 60 . The last letter $\mathrm{C}$ indicates that the specimen was wrapped with FRP.

\subsection{Instrumentation, testing and data acquisition}

All specimens were tested using a displacement controlled digital universal testing machine (Tinius Olsen Testing Machine Company, Horsham, Pennsylvania, capacity: 1000kN) by applying displacements. The load and deflection events of the experimental testing of specimens were recorded using high definition (HD) video camera with a speed of 30 frames/ sec. These videos were finally analyzed by post-processing of the HD images extracted from it employing DICT (Digital image correlation technique) using MATLAB R2013b. 


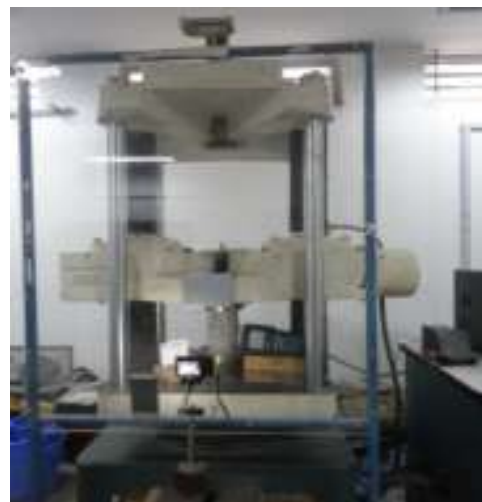

Fig. 3. Illustration of experimental setup

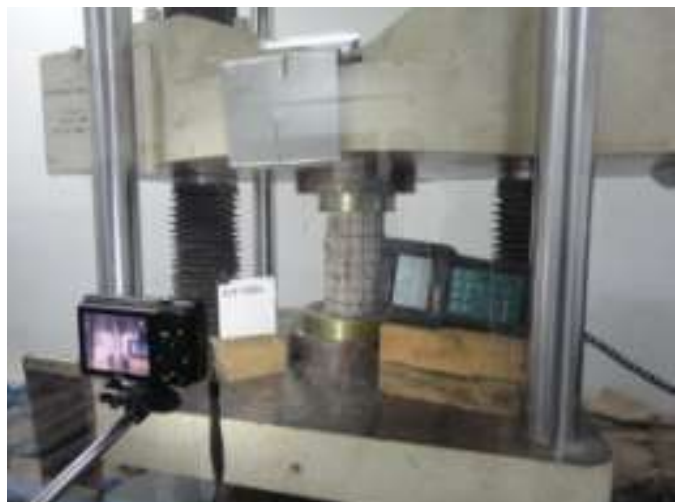

Fig. 4. Capturing experiment events with HD video camera

\section{Test Results And Discussion}

Table 1

\begin{tabular}{|l|l|l|l|l|l|}
\hline $\begin{array}{l}\text { Specimen } \\
\text { designation }\end{array}$ & $\begin{array}{l}\text { Fiber volume fraction } \\
(\mathrm{VF})\end{array}$ & $\begin{array}{l}\text { Fiber aspect ratio } \\
(\mathrm{AR})\end{array}$ & Confinement & $\begin{array}{l}\text { Peak Axial Stress } \\
(\mathrm{MPa})\end{array}$ & $\begin{array}{l}\text { Axial Strain at } \\
\text { Peak }\end{array}$ \\
\hline SCON & - & - & Unconfined & 21.2 & 0.0006 \\
\hline SCONC & - & - & Confined & 33.2 & 0.0013 \\
\hline SSF1.5-20 & $1.5 \%$ & 20 & Unconfined & 26.7 & 0.0009 \\
\hline SSF1.5-40 & $1.5 \%$ & 40 & Unconfined & 23.4 & 0.0009 \\
\hline SSF1.5-60 & $1.5 \%$ & 60 & Unconfined & 18.8 & 0.0011 \\
\hline SSF1.5-80 & $1.5 \%$ & 80 & Unconfined & 19.7 & 0.0012 \\
\hline SSF2-20 & $2.0 \%$ & Unconfined & 26.8 & 0.0009 \\
\hline SSF2-40 & $2.0 \%$ & Unconfined & 19.0 & 0.0010 \\
\hline SSF2-60 & $2.0 \%$ & Unconfined & 20.7 & 0.0015 \\
\hline SSF2-80 & $2.0 \%$ & Unconfined & 18.7 & 0.0013 \\
\hline SSF1.5-20C & $1.5 \%$ & Confined & 47.6 & 0.0015 \\
\hline SSF1.5-40C & $1.5 \%$ & 60 & Confined & 41.1 & 0.0012 \\
\hline SSF1.5-60C & $1.5 \%$ & 20 & Confined & 47.0 & 0.0020 \\
\hline SSF1.5-80C & $1.5 \%$ & 40 & Confined & 41.6 & 0.0017 \\
\hline SSF2-20C & $2.0 \%$ & Confined & 47.4 & 0.0015 \\
\hline SSF2-40C & $2.0 \%$ & Confined & 39.8 & 0.0015 \\
\hline SSF2-60C & $2.0 \%$ & 80 & Confined & 49.0 & 0.0019 \\
\hline SSF2-80C & $2.0 \%$ & 20 & Confined & 39.0 & 0.0017 \\
\hline
\end{tabular}

Table 1 presents the summary of results for all the 18 specimens that were tested. Peak axial stresses and axial strains at peak are shown in the rightmost two columns of the table. These results allow several significant observations be made on different aspects of the experimental study. In the following sections, these observations are presented under different titles.

\subsection{Effect of Confinement}

It is evident from the results reported in Table 1 that, FRP-confined control specimen SCONC exhibited higher load than that of unconfined control specimen SCON. Among rest of the 16 specimens which were reinforced with steel fiber, all confined cylinders exhibited much higher load than that of unconfined cylinders of same category (i.e. with same volume fraction and aspect ratio of steel fibers). This observation accords with those reported in many previous studies on FRP-wrapped concrete.

\subsection{Effect of aspect ratio (AR) of steel fibers}

The results presented in Table 1 revealed the effect of steel fiber aspect ratio (AR) on the behavior of SFRC specimens. It is evident from Table 1 and Fig. 5 that with the increase of aspect ratio (from 20 80), the peak axial stresses of both unconfined and FRP-confined cylinders slightly decrease for both group of specimens with volume fraction $1.5 \%$ and $2.0 \%$. This influence can be explained to the ability of steel fibers with lower aspect ratios to effectively control the initiation and propagation of initial cracks of SFRC specimens under increasing axial deformation [7,11]. On the other hand, the fibers with higher aspect ratios have been reported to be less effective in arresting crack propagation immediately after the formation of initial cracks [7,11]. In addition, for a given fiber diameter and volume fraction, the number of fiber increase with a decrease in the fiber aspect ratio, which results in a more scattered distribution leading to an increased likelihood for the path of cracks to cross through the fibers [12,27]. These properties of the shorter steel fibers make them more effective in providing internal confinement to concrete, which in turn leads to an improved compressive behavior of SFRC specimens manufactured with such fibers [28]. 


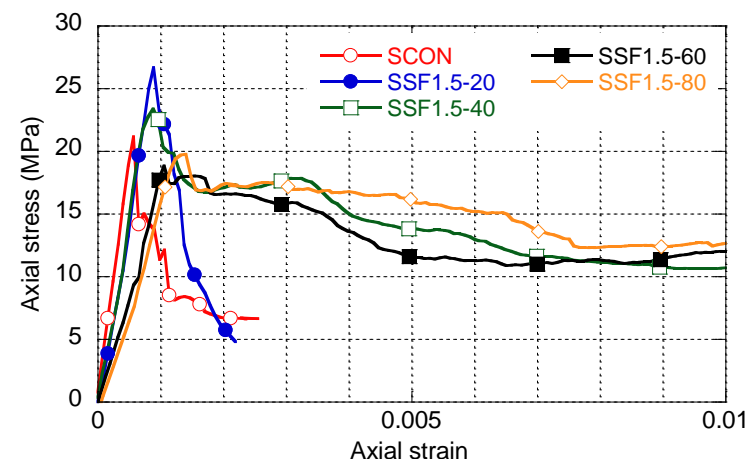

(a)

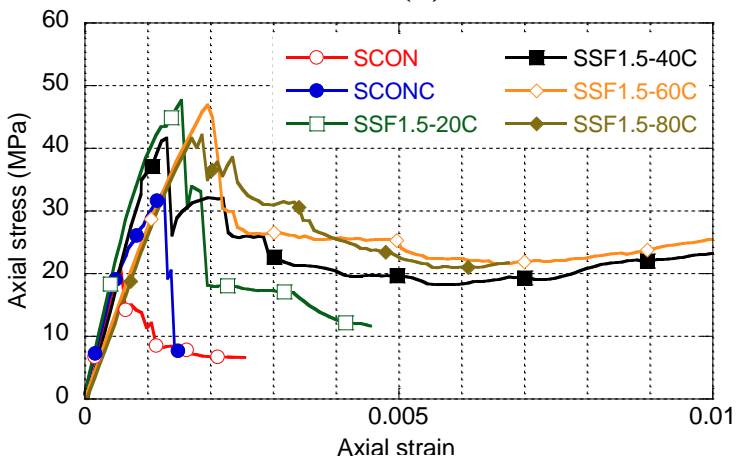

(c)

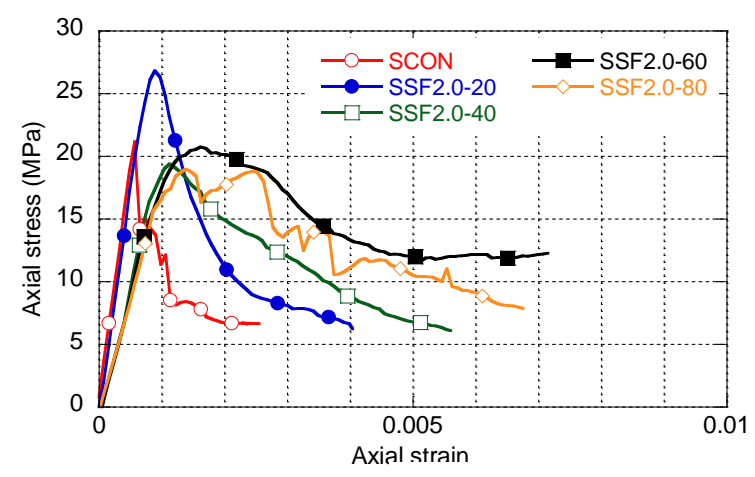

(b

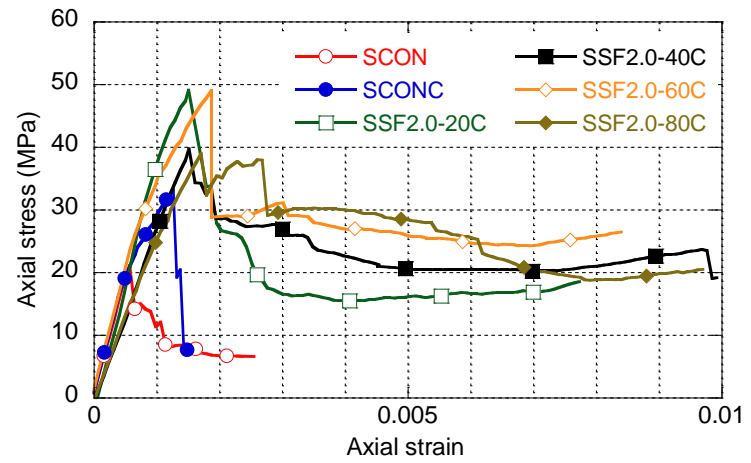

(d)

Fig. 5. Influence of fiber aspect ratio on compressive behavior of: (a) unconfined steel fiber reinforced concrete with $\mathrm{VF}=1.5$; (b) unconfined steel fiber reinforced concrete with $\mathrm{VF}=2.0$; (c) confined steel fiber reinforced concrete with $\mathrm{VF}=1.5$; (d) confined steel fiber reinforced concrete with $\mathrm{VF}=2.0$;

\subsection{Effect of volume fraction (VF) of steel fibers}

Fig. 6 presents the influence of the fiber volume fraction on the axial compressive behavior of the specimens. It is evident from the experimental data provided in Table 1 and from Fig. 6 that, although the presence of steel fiber increases the peak axial stresses for both confined and unconfined group of specimens, but no significant change of peak axial stress (and peak strain) has been observed in both confined and unconfined group due to increase of fiber volume ratio from $1.5 \%$ to $2 \%$.
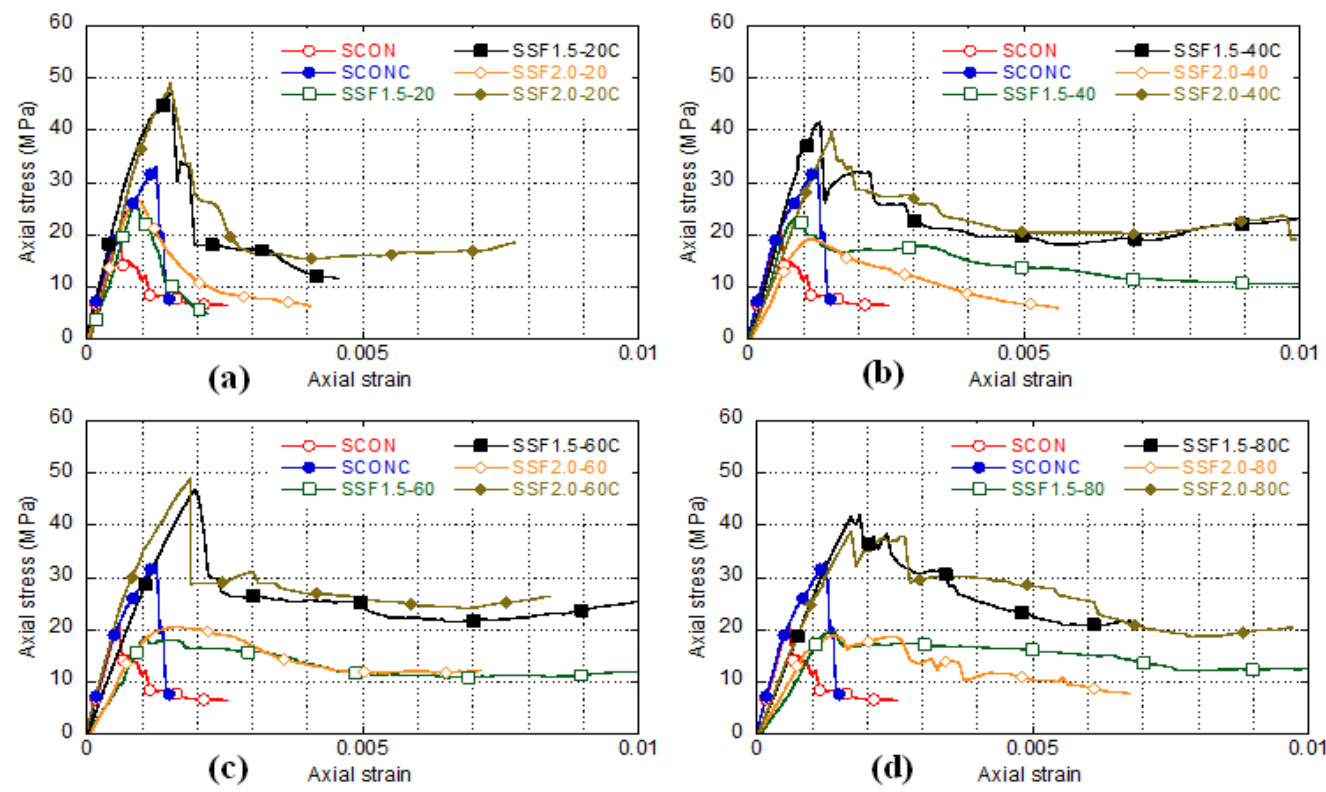

Fig. 6. Influence of fiber volume fraction on compressive behavior of: (a) SFRC with $A R=20$; (b) SFRC with AR = 40; (c) SFRC with $A R=60$; (d) SFRC with $A R=80$; 
Experimental Investigation of Axial Capacity and Energy Absorption of SFRC Columns Confined ..

\subsection{Axial strain and energy absorption capacity}

One of the most notable effect due to the presence of the steel fibers is the increase in axial strain at peak with respect to control specimens (for both confined and unconfined specimen groups) Fig. 5 and Fig. 6. In addition, Fig. 5 and Fig. 6 exhibit that the presence of fibers ensured a much higher strain before complete failure of the cylinders (for both confined and unconfined specimen groups). Besides, it is evident that the area under the stress strain curve for specimens with steel fiber is much larger than that of specimens without steel fiber. This behavior indicates that, concrete reinforced with internal steel fiber will absorb much higher energy than that of unreinforced ones.

\subsection{Lateral strain}

While observing lateral strain of the specimens, no significant patterns of lateral strain were found for change in volume fraction from $1.5 \%$ to $2.0 \%$ (for both confined and unconfined specimens).

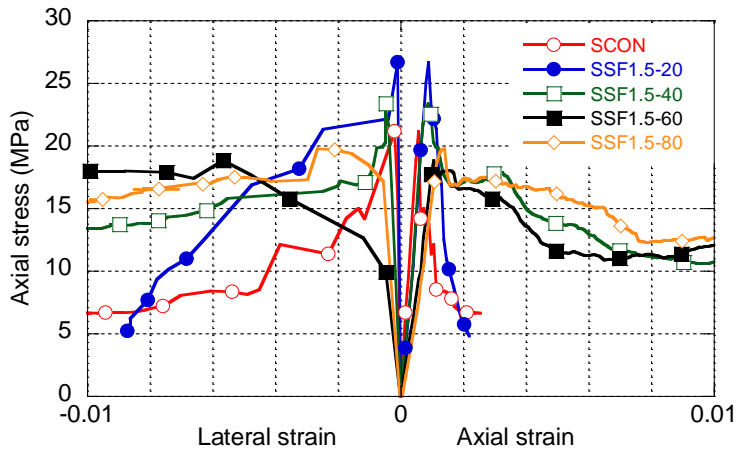

(a)

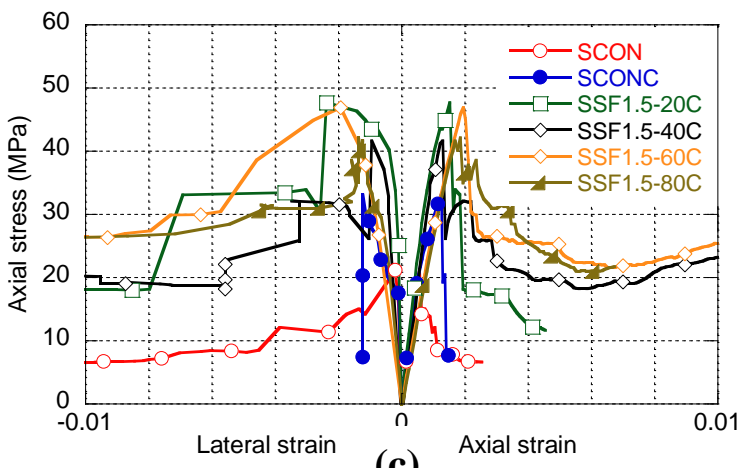

(c)

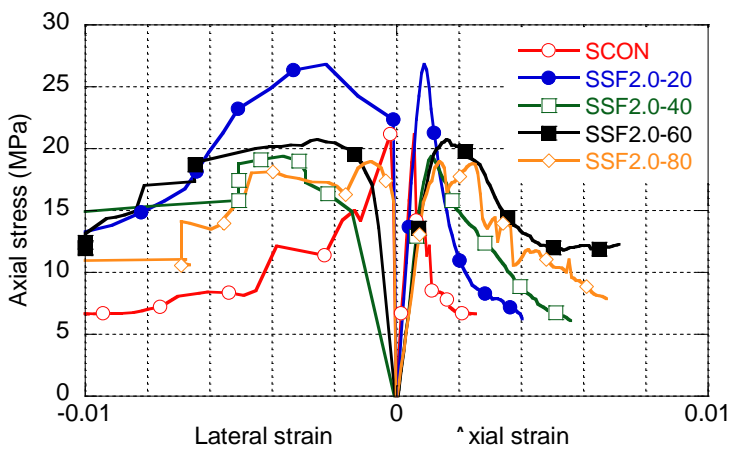

(b)

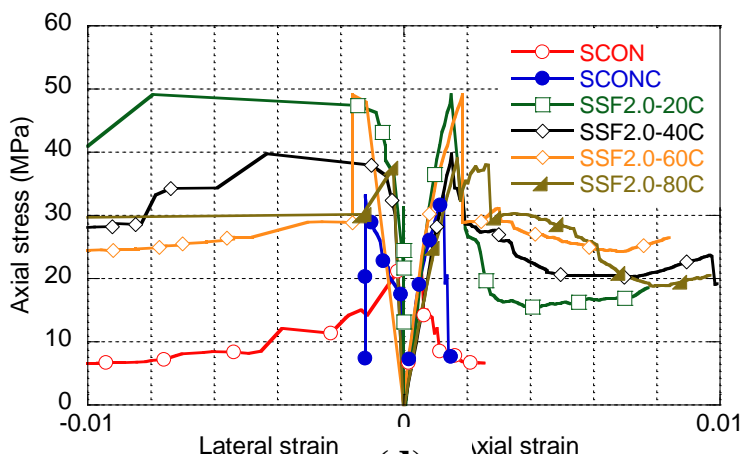

(d)

Fig. 7. Axial and Lateral Strain for: (a) \& (b) Unconfined series; (c) \& (d) Confined series

\section{Conclusion}

Based on the discussion and results presented in this study, the following conclusions can be drawn:

1) FRP confined cylinders exhibit greater axial stress than that of unconfined specimens.

2) The presence of steel fiber increases the peak axial stresses for both confined and unconfined group of concrete specimens.

3) No significant change of peak axial stress (and peak strain) occurs due to increase of fiber volume ratio from $1.5 \%$ to $2.0 \%$ (for both confined and unconfined groups).

4) With the increase of fiber aspect ratio, the peak axial stresses of both unconfined and FRP-confined cylinders slightly decrease.

5) Presence of the steel fibers results in increase of axial strain at peak with respect to control specimens (for both confined and unconfined specimen groups)

6) Concrete specimens reinforced with internal steel fiber absorbed much higher energy than that of unreinforced ones.

\section{References}

[1]. Lam L, Teng JG. Design-oriented stress-strain model for FRP-confined concrete in rectangular columns. Journal of Reinforced Plastics and Composites. 2003 Sep 1;22(13):1149-86. 
[2]. Lam L, Teng JG. Design-oriented stress-strain model for FRP-confined concrete. Construction and building materials. 2003 Oct 31;17(6):471-89.

[3]. Lim JC, Ozbakkaloglu T. Confinement model for FRP-confined high-strength concrete. J Compos Constr ASCE 2014;17(5):1-19.

[4]. Lim JC, Ozbakkaloglu T. Lateral strain-to-axial strain relationship of confined concrete. J Struct Eng ASCE 2014. http://dx.doi.org/10.1061/(ASCE)ST.1943-541X.0001094.

[5]. Soroushian P, Bayasi Z. Fiber type effects on the performance of steel fiber reinforced concrete. ACI Mater J 1991;88(2).

[6]. Nataraja MC, Dhang N, Gupta AP. Stress-strain curves for steel-fiber reinforced concrete under compression. Cem Concr Compos 1999;21(5):383-90.

[7]. Bhargava P, Sharma UK, Kaushik SK. Compressive stress-strain behavior of small scale steel fibre reinforced high strength concrete cylinders. J Adv Concr Technol 2006;4(1):109-21.

[8]. Holschemacher K, Muller T. Influence of fibre type on hardened properties of steel fiber reinforced concrete. Modern building materials, structures and techniques. In: Proceedings of the 9th international conference, Vilnius; 2007.

[9]. Bencardino F, Rizzuti L, Spadea G, Swamy RN. Stress-strain behavior of steel fiber-reinforced concrete in compression. J Mater Civ Eng 2008;20(3):255-63.

[10]. Paultre P, Eid R, Langlois Y, Levesque Y. Behavior of steel fiber-reinforced high-strength concrete columns under uniaxial compression. J Struct Eng 2010;136(10):1225-35.

[11]. Khalil WI, Gorgis IN, Mahdi ZR. Behavior of high performance fiber reinforced concrete column. J Eng Appl Sci 2012;7(11).

[12]. Ezeldin AS, Balaguru PN. Normal-and high-strength fiber-reinforced concrete under compression. J Mater Civ Eng 1992;4(4):41529.

[13]. Ding Y, Kusterle W. Compressive stress-strain relationship of steel fiber reinforced concrete at early age. Cem Concr Res 2000;30(10):1573-9.

[14]. Kholmyansky MM. Mechanical resistance of steel fiber reinforced concrete to axial load. J Mater Civ Eng 2002;14(4):311-9.

[15]. Ramesh K, Seshu DR, Prabhakar M. Constitutive behaviour of confined fibre reinforced concrete under axial compression. Cem Concr Compos 2003;25(3):343-50.

[16]. Sukontasukkul P, Mindess S, Banthia N. Properties of confined fibre-reinforced concrete under uniaxial compressive impact. Cem Concr Res 2005;35(1):11-8.

[17]. Thomas J, Ramaswamy A. Mechanical properties of steel fiber-reinforced concrete. J Mater Civ Eng 2007;19(5):385-92.

[18]. Xu LH, Xia DT, Xia GZ, Chi Y. Effect of steel fiber and polypropylene fiber on the strength of high strength concrete. J Wuhan Univ Technol 2007;29(4):58-60.

[19]. Holschemacher K, Mueller T, Ribakov Y. Effect of steel fibres on mechanical properties of high-strength concrete. Mater Des 2010;31(5):2604-15.

[20]. Ayan E, Saatciog `lu O, Turanli L. Parameter optimization on compressive strength of steel fiber reinforced high strength concrete. Constr Build Mater 2011;25(6):2837-44

[21]. Ou YC, Tsai MS, Liu KY, Chang KC. Compressive behavior of steel-fiberreinforced concrete with a high reinforcing index. J Mater Civ Eng 2011;24(2):207-15.

[22]. Chi Y, Xu L, Zhang Y. Experimental study on hybrid fiber-reinforced concrete subjected to uniaxial compression. J Mater Civ Eng 2012;26(2):211-8.

[23]. Hassan AMT, Jones SW, Mahmud GH. Experimental test methods to determine the uniaxial tensile and compressive behaviour of ultra high performance fibre reinforced concrete (UHPFRC). Constr Build Mater 2012;37:874-82.

[24]. Tokgoz S, Dundar C. Tests of eccentrically loaded L-shaped section steel fibre high strength reinforced concrete and composite columns. Eng Struct 2012;38:134-41.

[25]. Wang S, Zhang MH, Quek ST. Mechanical behavior of fiber-reinforced highstrength concrete subjected to high strain-rate compressive loading. Constr Build Mater 2012;31:1-11.

[26]. Caballero-Morrison KE, Bonet JL, Navarro-Gregori J, Serna-Ros P. An experimental study of steel fiber-reinforced high-strength concrete slender columns under cyclic loading. Eng Struct 2013;57:565-77.

[27]. Vandewalle L. Postcracking behaviour of hybrid steel fiber reinforced concrete. In: Proc 6th int conf on fracture mechanics of concrete and concrete structures-FraMCoS, vol. 6; 2007. p. 1367-75.

[28]. Tianyu Xie, Togay Ozbakkaloglu. Behavior of steel fiber-reinforced high-strength concrete-filled FRP tube columns under axial compression. Eng Struct 2015;90:158-171. 